\title{
Optimization of Biodiesel Production From Bakul Oil
}

\author{
Mohammad Kaniz Ferdous $^{1 *}$, M. Rahim Uddin ${ }^{1}$, M. Rakib Uddin ${ }^{1}$, Maksudur R. Khan ${ }^{1,2,}$, M. A. Islam ${ }^{1}$ \\ ${ }^{1}$ Department of Chemical Engineering and Polymer Science, Shahjalal University of Science and Technology \\ (SUST), Sylhet 3114, Bangladesh. \\ ${ }^{2}$ Faculty of Chemical and Natural Resources Engineering, Universiti Malaysia Pahang, 26300 Gambang, Kuantan, \\ Pahang, Malaysia.
}

\begin{abstract}
:
In this paper, biodiesel production from Bakul oil (Mimusops Elengi) by three-step method and optimization were studied by the application of factorial design. Bakul Oil (BO) was extracted from Bakul seeds by press method and soxhlet extraction method. Bakul seed was collected from the local sources. The raw oil, containing $11.1 \mathrm{wt} \%$ Free Fatty Acid (FFA) and viscosity was $76.62 \mathrm{~mm}^{2} / \mathrm{s}$. Because of higher FFA content of BO transesterification method can't be applied, so three-step method was conducted for biodiesel production and optimization. In the three-step method, the first step was saponification of the oil followed by acidification to produce FFA and finally esterification of FFA to produce biodiesel. The reaction parameters in saponification, acidification and esterification reaction were optimized. Silica gel was used during esterification reaction to adsorb water produced in the reaction and silica gel to FFA ratio was 1:10 wt/wt. Hence the reaction rate was increased and finally the FFA was reduced to $0.70 \mathrm{wt} \%$. A factorial design was studied for esterification reaction and developed to obtain the higher yield of biodiesel. Finally various properties of biodiesel such as FFA, viscosity, specific gravity, cetane index, pour point, flash point were measured and compared with biodiesel and petro-diesel standard.
\end{abstract}

\section{Introduction}

Biodiesel is a non-toxic, biodegradable, renewable fuel that can be produced from a range of organic feedstock including fresh or waste vegetable oils, animal fats, and oilseed plants. Biodiesel has significantly lower emissions than petroleum-based diesel when it is burned, whether used in its pure form or blended with petroleum diesel. It does not contribute to a net rise in the level of carbon dioxide in the atmosphere and leads to minimize the intensity of greenhouse effect [1]. Petroleum based fuel is used extensively by human civilization and the reserve is depleting day by day. Due to the limited reserve and the environmental concern alternative renewable energy sources, such as solar, wind, tidal, biomasses are being investigated in last two decades. Among these renewable energy sources biodiesel is a prominent one because this can be produced form wide range of renewable sources and this can be used directly in automobile diesel engine without any modification of the engine. Also it can be used in various ratios with petro-diesel [1]. Biodiesel is receiving increased attention as an alternative renewable diesel fuel. It has higher oxygen content than petro-diesel and its use in diesel engine have shown great reductions in emission of particulate matter, carbon monoxide, sulfur, polyaromatics, hydrocarbons, smoke and noise [2].

Depending upon the climate and soil conditions, different countries are looking for different types of vegetable oils as substitutes for diesel fuels. For example, soybean oil in US, rapeseed and sunflower oil in Europe, palm oil in South-east Asia (mainly Malaysia and Indonesia) and coconut oil in Philippines are being considered [3].
Non-edible plant oil has been found to be promising crude oil for the production of biodiesel. The use of nonedible oil for biodiesel production compared with edible oil is very significant in developing countries because of the tremendous demand of edible oil as food and they are far too expensive to be used as fuel at present $[4,5]$.

Biodiesel mainly produced from vegetable oil by transesterification reaction. Transesterification reaction can be catalyzed by both homogeneous (alkalis and acids) and heterogeneous catalysts [6]. Although, alkalicatalyzed transesterification reaction is much faster than acid catalyst, it is not suitable for $\mathrm{BO}$ transesterification because BO contains large amounts of FFA. Alkaline catalysts are very sensitive to FFA. FFA can react with an alkali catalyst to produce soap and water, which diminishes the ester yield [7, 8]. Homogeneous acid catalyzed transesterification reaction is about 4000 times slower than the homogeneous base-catalyzed transesterification reaction and hence is not popular for industrial production of biodiesel [9]. Morshed et al. [10] proposed a three-step method for the production of biodiesel from high FFA containing rubber seed oil .

Biodiesel was synthesized from BO by three-step method where $100 \%$ FFA was produced from oil by saponification followed by acidification reactions. In the final step esterification of FFA was conducted in presence of acid catalyst. Various reaction parameters were optimized. Factorial design was carried out for optimization of the biodiesel production process. 


\section{Materials and Methods}

\subsection{Chemicals}

Methanol (99-100\%), ethanol (99-100\%), sodium hydroxide pellets $(96 \%)$, potassium hydroxide pellets (>84\%), phenolphthalein ( $\mathrm{pH} 8.2-9.8)$, acetone (99\%), diethyl ether, hydrochloric acid (37\%), sulfuric acid (98\%), iodine, sodium iodide, bromine, carbon tetrachloride, glacial acetic acid, potassium dichromate etc. All the chemicals were used as analytical reagent grade.

\subsection{Extraction of oil}

Bakul seeds were collected from gardens and road side of Sylhet region. Oil from the seeds was extracted by mechanical press and soxhlet extraction method. A vertical, manual operated, cylindrical (4.3 cm ID) mechanical press was constructed which have a spiral screw that conveys the mass from the hoper to pressure raising area. Slow and continuous rotation of the press allows raising sufficient pressure for the extraction of oil. After oil extraction it was filtered. A Soxhlet Extraction unit was used for oil extraction, where hexane was refluxed for $4 \mathrm{~h}$ for a given amount of kernel mass. The oil content of Bakul seed was found $20 \%$ (v/w) by press method and $30 \%$ by soxhlet extraction method. The oil was stored at room temperature.

\subsection{Preparation of biodiesel from BO}

For saponification process required amount of $\mathrm{BO}$ was taken in a three necked flask and mixed with different stoichiometric amount of aqueous sodium hydroxide solution [10]. The mixture was heated under reflux with vigorous stirring at temperature of $100{ }^{0} \mathrm{C}$ for different time. After saponification, produced sodium soap solution was treated with different stoichiometric amount of concentrated hydrochloric acid at a temperature of 65 $70{ }^{0} \mathrm{C}$. After dissolving the soap, the fatty acid contents were separated in separatory funnel. Hot water wash was given to produced FFA for removing mineral acid from the fatty acid. The FFA content was determined by titrametric method. The different molar ratio of soap to hydrochloric acid was optimized. When acidification was completed, produced FFA was reacted with different stoichiometric amount of methanol under reflux with vigorous stirring at different temperature, catalyst concentration, different molar ratio of methanol to FFA and different time. All the reaction parameters were optimized. Silica gel was used during esterification reaction to adsorb water produced in esterification reaction. After preparing the biodiesel from $\mathrm{BO}$ various physico-chemical properties were measured and compared with the standard biodiesel petro-diesel.

\subsection{Analytical methods for oil and biodiesel}

To determine FFA of sample and biodiesel, $1 \mathrm{~mL}$ of oil and biodiesel were weighed in $\mathrm{gm}$, then dispersed in $5 \mathrm{~mL}$ diethyl-ether solution followed by titration against $0.1 \mathrm{M} \mathrm{KOH} \mathrm{[11].} \mathrm{Saponification} \mathrm{value} \mathrm{(SV)} \mathrm{was}$ determined by method described by Jeffery et al., [11]. To determined SV. 2 gm sample was taken in $50 \mathrm{~mL}$ alcoholic $\mathrm{KOH}$ then heated at $65{ }^{\circ} \mathrm{C}$ with vigorous stirring for $30 \mathrm{~min}$ and titrated against $0.5 \mathrm{M}$ hydrochloric acid. The iodine value (IV) were determined by titrating $0.01 \mathrm{~N}$ sodium thiosulfate to the mixture of tested fuel and chemical reagents until the disappearance of the blue color based on the analysis methods of American Oil Chemist's Society. IV was calculated by the following Eq. 1:

Iodine value $=(\mathrm{B}-\mathrm{S}) \times \mathrm{N} \times 0.001269 / \mathrm{W}$

where $\mathrm{S}$ and $\mathrm{B}$ are the amounts (in unit of $\mathrm{ml}$ ) of sodium thiosulfate titrated for the tested sample and blank sample, respectively; $\mathrm{N}$ is the molar concentration (in unit of $\mathrm{mol} / \mathrm{L}$ ) of sodium thiosulfate; and $\mathrm{W}$ is the weight (in unit of $g$ ) of the tested sample.

Physical properties such as color, moisture content and density of the oil were determined by following ASTM D 1500, ASTM D 1744 (Karl fisher method), ASTM D 1480/81 and ASTM D 240 respectively. Viscosity, flash point, pour point and cloud point were determined by standards ASTM D445, ASTM D 93 (Pensky- Martens Flashpoint Apparatus, Lazer Scientific Inc, Germany), ASTM D 2500 and ASTM D 97 respectively.

\section{Results and Discussion}

\subsection{Characterization of $\mathrm{BO}$}

The properties of BO such as viscosity, specific gravity, moisture content, saponification value, pour point, cloud point etc were measured and presented in Table 1.

Table 1. Properties of BO

\begin{tabular}{lc}
\hline \multicolumn{1}{c}{ Properties } & $\begin{array}{c}\text { Experimental } \\
\text { value }\end{array}$ \\
\hline Physical state & Liquid \\
Color & $\begin{array}{c}\text { Dark Brown } \\
\text { Specific gravity at } 25^{\circ} \mathrm{C}\end{array}$ \\
Kinematic viscosity, $\mathrm{mm}^{2} / \mathrm{s}$ & 0.89 \\
at $40{ }^{\circ} \mathrm{C}$ & 76.6 \\
FFA content $(\mathrm{wt} \%$ of oil) & 11.1 \\
Saponification value $(\mathrm{mg}$ of & 228 \\
KOH/gm of oil) & 15 \\
Cloud point $\left({ }^{\circ} \mathrm{C}\right)$ & 6 \\
Pour point $\left({ }^{\circ} \mathrm{C}\right)$ & \\
\hline
\end{tabular}

\subsection{Biodiesel prepared by three-step method}

3.2.1 FFA preparation: FFA was prepared from BO by saponification followed by acidification. Saponification was done by the method described above. Saponification was done with different stoichiometric amount of $\mathrm{NaOH}$. After saponification and acidification FFA was produced. The results are present in Fig. 1. From the Fig. 1 it can be 
seen that, the optimum molar ratio of oil to $\mathrm{NaOH}$ was $1: 2$ and reaction time was $120 \mathrm{~min}$.

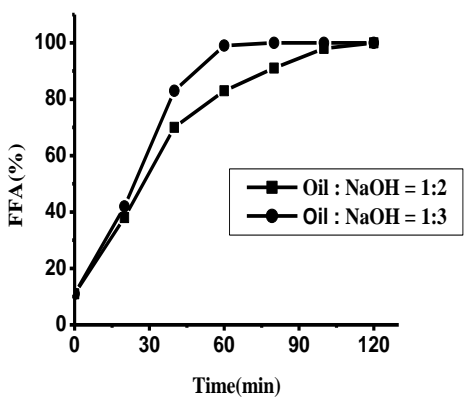

Fig. 1: Preparation of FFA from BO through saponification and acidification [Reaction temperature = $100{ }^{\circ} \mathrm{C}$ under reflux with vigorous stirring].

3.2.2 Biodiesel Preparation from FFA: The methanol to FFA molar ratio, catalyst concentration, temperature and time are the important parameters that affecting the FFA conversion to biodiesel. The effect of methanol to FFA molar ratio, catalyst concentration and temperature on conversion of FFA was investigated. The results are shown in Fig. 2, 3 and 4. From the Fig. 2, 3 and 4, it was found that the FFA conversion to biodiesel was $99 \%$ at $6: 1$ molar ratio of methanol to FFA, $5 \mathrm{wt} \%$ catalyst $(\mathrm{HCl})$ concentration, $60{ }^{\circ} \mathrm{C}$ temperature.

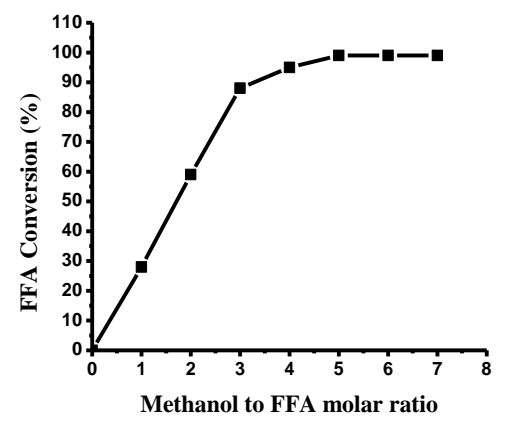

Fig. 2: Effect of Methanol to FFA molar ratio on FFA conversion [temperature $60{ }^{\circ} \mathrm{C}$, catalyst $(\mathrm{HCl}) 5 \mathrm{wt} \%$ of FFA, time 120 min under reflux with vigorous stirring].

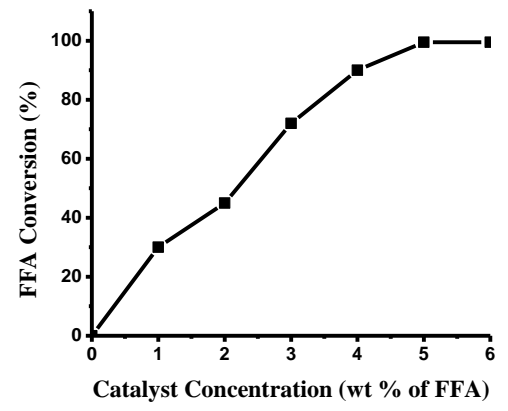

Fig. 3: Effect of catalyst $(\mathrm{HCl})$ concentration on esterification reaction [Reaction temperature $60{ }^{0} \mathrm{C}$, methanol to FFA ratio 6:1, Reaction time $120 \mathrm{~min}$, under reflux with vigorous stirring].

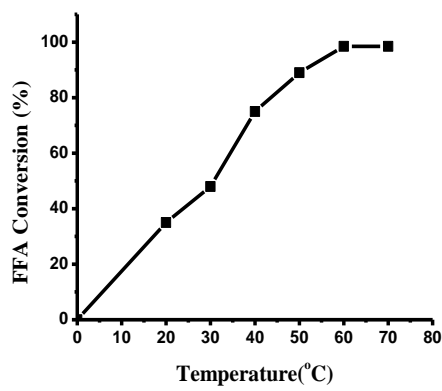

Fig. 4: Effect of Temperature on esterification reaction [Catalyst $(\mathrm{HCl})$ concentration $5 \mathrm{wt} \%$ of FFA, methanol to FFA ratio 6:1, Reaction time $120 \mathrm{~min}$, under reflux with vigorous stirring].

\subsubsection{Effect of silica gel on Esterification:}

Silica gel adsorb the water produced in esterification reaction, hence the reaction rate is increased. The reaction time significantly reduced from $120 \mathrm{~min}$ to only $80 \mathrm{~min}$ for the desired FFA conversion. The experimental results are shown in Fig. 5.

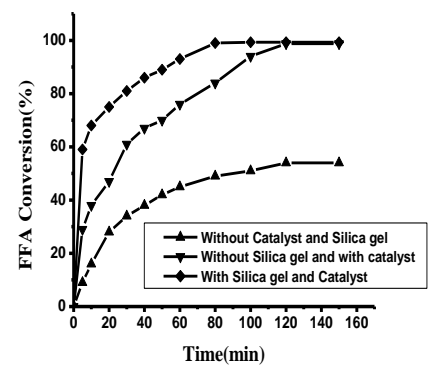

Fig. 5: Conversion of FFA to biodiesel in absence and presence of silica gel [Reaction temp. $60{ }^{0} \mathrm{C}$, Catalyst $(\mathrm{HCl})$ concentration $5.0 \%$ wt of FFA and Reaction time 120 min under reflux with vigorous stirring].

\subsection{Optimization study}

Four factors (methanol to FFA molar ratio, catalyst concentration, temperature and reaction time) affect the biodiesel production process from BO. To study the optimization of process, a factorial design was carried out. The experiments were carried out according to halfReplicate of $2^{4}$ full factorial design. Table 2 shows the decoding values for methanol to FFA molar ratio, catalyst concentration, reaction temperature and reaction time. Eight set of experiments were run for the factorial design and the results are shown in Table 3 . Table 4 presents the values of sample variances.

Table 2. Decoding values of independent variables used in the experimental design

\begin{tabular}{lcc}
\hline Factors & Max. $(+1)$ & Min. $(-1)$ \\
\hline Molar ratio $\left(\mathrm{X}_{1}\right)$ & 8 & 3 \\
\hline Catalyst conc. $\left(\mathrm{X}_{2}\right)$ & 6 & 2 \\
\hline Temperature, ${ }^{\circ} \mathrm{C}\left(\mathrm{X}_{3}\right)$ & 60 & 40 \\
\hline Time $(\min )\left(\mathrm{X}_{4}\right)$ & 90 & 30 \\
\hline Table 3. Design of the experiment using coded value
\end{tabular}




\begin{tabular}{|c|c|c|c|c|c|c|c|c|c|c|c|c|}
\hline $\begin{array}{c}\text { No. of } \\
\text { runs }\end{array}$ & $\mathrm{X}_{\mathrm{o}}$ & $\mathrm{X}_{1}$ & $\mathrm{X}_{2}$ & $\mathrm{X}_{3}$ & $\mathrm{X}_{4}$ & $\mathrm{Y}_{1}$ & $\mathrm{Y}_{2}$ & $\mathrm{Y}_{3}$ & $\mathrm{Y}_{4}$ & $\mathrm{Y}_{5}$ & $\bar{Y}$ & $\mathrm{~S}_{\mathrm{i}}{ }^{2}$ \\
\hline 1 & +1 & +1 & +1 & +1 & +1 & 98.9 & 98.3 & 97.8 & 99.0 & 98.2 & 98.44 & 0.26 \\
\hline 2 & +1 & +1 & +1 & -1 & -1 & 67.4 & 64.7 & 68.1 & 67.5 & 65.4 & 66.62 & 2.2 \\
\hline 3 & +1 & +1 & -1 & +1 & -1 & 91.7 & 92.8 & 90.7 & 92.0 & 89.9 & 91.42 & 1.29 \\
\hline 4 & +1 & +1 & -1 & -1 & +1 & 74.1 & 71.8 & 75.4 & 72.6 & 76.1 & 74.0 & 3.3 \\
\hline 5 & +1 & -1 & +1 & +1 & -1 & 78.7 & 79.5 & 76.5 & 79.3 & 77.2 & 78.24 & 1.76 \\
\hline 6 & +1 & -1 & +1 & -1 & +1 & 43.7 & 47.9 & 46.8 & 46.9 & 45.7 & 46.2 & 2.56 \\
\hline 7 & +1 & -1 & -1 & +1 & +1 & 54.1 & 60.6 & 63.3 & 60.4 & 59.9 & 61.26 & 1.98 \\
\hline 8 & +1 & -1 & -1 & -1 & -1 & 42.6 & 46.7 & 45.8 & 41.9 & 46.8 & 44.76 & 5.46 \\
\hline & & & & & & & & & & & $\sum \bar{Y}=$ & $\sum \mathrm{S}_{\mathrm{i}}{ }^{2}=$ \\
& & & & & & & & & & & 560.94 & 18.81 \\
\hline
\end{tabular}

Table 4. Sample Variances

\begin{tabular}{|l|l|l|l|}
\hline $\mathrm{S}_{1}{ }^{2}$ & 0.26 & $\mathrm{~S}_{5}{ }^{2}$ & 1.76 \\
\hline $\mathrm{S}_{2}{ }^{2}$ & 2.20 & $\mathrm{~S}_{6}{ }^{2}$ & 2.56 \\
\hline $\mathrm{S}_{3}{ }^{2}$ & 1.29 & $\mathrm{~S}_{7}{ }^{2}$ & 1.98 \\
\hline $\mathrm{S}_{4}{ }^{2}$ & 3.30 & $\mathrm{~S}_{8}{ }^{2}$ & 5.46 \\
\hline
\end{tabular}

Where $\mathrm{Y}$ is the conversion of FFA to biodiesel in esterification reaction and $\bar{Y}$ is average value of $\mathrm{Y}$.

$\hat{\mathrm{Y}}=\mathrm{b}_{\mathrm{o}}+\mathrm{b}_{1} \mathrm{X}_{1}+\mathrm{b}_{2} \mathrm{X}_{2}+\mathrm{b}_{3} \mathrm{X}_{3}+\mathrm{b}_{4} \mathrm{X}_{4}+$

$b_{12} x_{12}+b_{13} x_{13}+b_{23} x_{23}$

The sample variances were determined and tested for homogeneity on the basis of Cochran's criterion. It was found that the sample variances are homogeneous for the significance level $\alpha=0.05$ and the number of degrees of freedom $v_{1}=4$ and $v_{2}=8$ and the error mean square was 2.36. The complete regression equation describes the contributions of the various factors on the outcome (response) of the biodiesel conversion.

$\hat{\mathrm{Y}}=70.11+12.50 \mathrm{X}_{1}+2.25 \mathrm{X}_{2}+12.22 \mathrm{X}_{3}-$

$2.34 \mathrm{X}_{12}+3.74 \mathrm{X}_{23}$

The coefficients of the regression equation were estimated and the significance of the coefficients was tested using the student T-test. Only one coefficient appeared as insignificant for the significance level $\alpha=$ 0.05. Neglecting the insignificant coefficient the final regression equation becomes as:

Using the Fisher's test the adequacy fitness of the regression equation was determined. With $\alpha=0.20, v_{1}=$ 2 and $v_{2}=32$ the tabulated value of Fisher's F was 1.7 where as our experimental value was 0.24 . Therefore the equation fits in the experiment.

\subsection{Properties of biodiesel}

The properties of produced biodiesel such as viscosity, FFA content, moisture content, pour point, cloud point, saponification value, iodine value, specific gravity were presented in Table 5 and compared with standard biodiesel and diesel values. The reaction yield was $80 \%$.

Table 5. Properties of biodiesel produced from BO by three-step method and comparison with standard biodiesel and diesel values.

\begin{tabular}{lccc}
\hline \multicolumn{1}{c}{ Properties } & $\begin{array}{c}\text { Produced } \\
\text { biodiesel } \\
\text { value }\end{array}$ & $\begin{array}{c}\text { Biodiesel } \\
\text { Standard } \\
{[10,12]}\end{array}$ & $\begin{array}{c}\text { Diesel } \\
\text { standard } \\
{[12]}\end{array}$ \\
\hline $\begin{array}{l}\text { Specific gravity, } \\
\text { at } 25^{\circ} \mathrm{C}\end{array}$ & 0.82 & $\begin{array}{c}0.88(\mathrm{at} \\
\left.15.5^{0} \mathrm{C}\right)\end{array}$ & $\begin{array}{c}0.85(\mathrm{at} \\
\left.15.5^{0} \mathrm{C}\right)\end{array}$ \\
$\begin{array}{l}\text { Kinematic } \\
\text { viscosity } \\
\left(\mathrm{mm}^{2} / \mathrm{s}\right) \text {, at } 40^{\circ} \mathrm{C}\end{array}$ & 3.87 & $1.9-6.0$ & $1.3-4.1$ \\
$\begin{array}{l}\text { FFA content } \\
(\% \mathrm{wt})\end{array}$ & 0.70 & - & - \\
$\begin{array}{l}\text { Moisture content } \\
(\%)\end{array}$ & 0.08 & $0.05 \%$ & 0.161 \\
$\begin{array}{l}\text { Saponification } \\
\text { value }\end{array}$ & 152 & - & - \\
Flash point $\left({ }^{\circ} \mathrm{C}\right)$ & 140 & 100 to & 60 to 80 \\
$\begin{array}{l}\text { Iodine value } \\
\text { Cloud point }\left({ }^{\circ} \mathrm{C}\right)\end{array}$ & 85 & - & - \\
Pour point $\left({ }^{\circ} \mathrm{C}\right)$ & -3 & -3 to 12 & -15 to 5 \\
Cetane Index & 53 & -15 to 10 & -35 to -15 \\
\hline
\end{tabular}

\section{Conclusion}


Biodiesel was prepared from BO by three-step method, in first step aqueous sodium hydroxide solution was used for saponification, the molar ratio of oil to $\mathrm{NaOH}$ and reaction time were optimized. The optimum molar ratio for saponification by aqueous sodium hydroxide was 1:2 oil to $\mathrm{NaOH}$ and reaction time was $120 \mathrm{~min}$ at $100{ }^{\circ} \mathrm{C}$. In acidification the molar ratio of soap to hydrochloric acid was 1:2 for sodium soap. In Esterification the optimum molar ratio of methanol to FFA was $6: 1$, the catalyst $(\mathrm{HCl})$ concentration was $5 \mathrm{wt} \%$ of FFA, the reaction temperature was $60^{\circ} \mathrm{C}$ and the reaction time was $120 \mathrm{~min}$, with silica gel reaction time was reduced to $80 \mathrm{~min}$ and FFA content was reduced to $0.70 \%$. A factorial design was applied to find the optimum conditions for

\section{References}

[1]. Prafulla, D. Patil, Shuguang D. (2009), Optimization of biodiesel production from edible and non-edible vegetable oils, Fuel , 88: 1302-1306

[2]. Knothe, G., Gerpen, J.V. and Krahl, J. (2005), The Biodiesel Handbook, AOCS Press, Illinois

[3]. Korbitz, W. (1999), Biodiesel production in Europe and North America, an encouraging prospect, Renewable Energy, 16: 1078-1083

[4]. Mustafa, B. (2011), Potential alternatives to edible oils for biodiesel production - a review of current work, Energy Conversion and Management, 52(2): 1479-1492

[5]. Arjun, B.C., Martin, S.T., Suzanne, M.B., Chris, K.W. and Rafiqul, M.I. (2008), Non-edible plant oils as new sources for biodiesel production, International Journal of Molecular Science, 9(2): 169-180

[6]. Vicente, G., Martínez, M., and Aracil, J. (2004), Integrated biodiesel production: a comparison of different homogeneous catalysts systems, Bioresource Technology, 92(3): 297-305

\section{Nomenclature}

\begin{tabular}{ccc}
\hline Symbol & Meaning & Unit \\
\hline $\mathrm{M}$ & Molarity & $\mathrm{Mol} / \mathrm{L}$ \\
$\mathrm{N}$ & Normality & Equivalent $\mathrm{mol} / \mathrm{L}$ \\
\hline
\end{tabular}

esterification reaction. At optimum conditions 99\% conversion of the FFA to biodiesel was obtained. The properties of produced biodiesel such as viscosity, specific gravity, cloud point, pour point, flash point, cetane number are nearest to the petro-diesel. The present experimental results support that produced biodiesel from BO by this method can be successfully used as diesel.

\section{Acknowledgement}

The authors express their deep gratitude to the University Grant Commission (UGC) for financial support to conduct this research.

[7]. Zang, Y., Dube, M.A., McLean, D.D. and Kates, M. (2003), Biodiesel production from waste cooking oil: process design and technological assessment, Bioresource Technology, 89:1-16

[8]. Usta, N., Ozturk, E., Can, O., Conkur, E.S., Nas, S. and Con, A.H. (2005), Combustion of biodiesel fuel produced from hazelnut soapstock/waste sunflower oil mixture in a diesel engine, Energy Conversion and Management, 46: 741-755

[9]. Freedman, B., Pryde, E.H. and Mounts, T.L. (1984), Variables affecting the yields of fatty esters from transesterified vegetable oils, JAOCS, 61(10): 16381643

[10]. Morshed, M., Ferdous, K., Khan, Maksudur, R., Mazumder, M.S.I., Islam, M.A., and Uddin, Md. T. (2011), Rubber seed oil as a potential source for biodiesel production in Bangladesh, Fuel, 90: 29812986

[11]. Jeffery, G.H., Bassett, J., Mendham, J. and Denney, R.C. (1991), Vogel's textbook of quantitative chemical analysis, $5^{\text {th }}$ edition, UK: Longman Scientific and Technical: 308-309

[12]. Joshi, R.M. and Pegg, M.J. (2007), Flow properties of biodiesel fuel blends at low temperatures, Fuel, 86: 143-151 